\title{
EFFECT OF TISSUE CONDITIONER ON SURFACE INTEGRITY OF DIFFERENT NON-METALLIC DENTURE BASE MATERIALS
}

\author{
Hamada Zaki Mahross Atia*
}

\begin{abstract}
Purpose: The purpose of this study was to investigate the effect of tissue conditioner leached out solvent contents on the surface roughness of heat-polymerized acrylic and visible light activated denture base materials.

Methods: A total of 40 square-shaped specimens ( $10 \times 10 \times 2 \mathrm{~mm})$ were constructed from heatpolymerized acrylic (Ecocryl) (Group A) and visible light cured (Eclipse) resins (Group B); each of which 20). The specimens were further divided into four subgroups ( $n=10)$; Group AI: Heat cured acrylic resin control group. Group AII: Heat cured acrylic resin specimens lined with tissue conditioner material. Group BI: Light cured resin control group. Group BII: Light cured resin specimens lined with tissue conditioner material. The initial (IRa) and final (FRa) surface roughness measurements were performed by using MarSurfPS1 profilometer after and before application of tissue conditioner on the specimens. The data was collected and statistically analyzed using paired sample $t$-test and independent $t$-test at the significance level of $(\alpha=0.05)$.
\end{abstract}

Results: There were a significant difference in surface roughness between group AI and AII $(p<0.05)$. A significance difference was also found between group BI and BII $(p<0.05)$. However, there was no significant difference between group AII and BII $(p>0.05)$.

Conclusions: The polished surface of the denture base material has changed with the using of tissue conditioner. The heat cured acrylic resin which used as denture base material was more resistant to solvent contents of tissue conditioner than visible light cured resin.

KEYWORDS: Tissue conditioner, Surface roughness, Profilometer, Acrylic resin.

\section{INTRODUCTION}

Tissue conditioners are soft, resilient materials used as interim reliners and during the healing phase after implant placement to treat inflamed, irritated, distorted tissue ${ }^{[1]}$. Moreover, they are effective in patients wearing non-metallic complete, partial or maxillofacial prostheses for several purposes including the conditioning of abused denture bearing mucosa, to increase serviceable life of prosthesis, to retain overdenture bar attachments, to retain intra/ extra oral prosthesis, to compensate for the volumetric shrinkage of acrylic resin denture ${ }^{[2,3]}$.

\footnotetext{
* Lecturer of Removable Prosthodontics, Faculty of Dental Medicine, Al-Azhar University, Cairo (Boys), Egypt.
} 
The increased wearing of dentures leads to irritation of the soft tissues, depriving it from blood supply and leading to resorption of the supporting bony foundation. The application of tissue conditioners has advocated temporarily to the fitting surface of the denture for allowing more even stress distributions. As that permitting the mucosal tissue to return to its normal shape and resolving any inflammation of the denture bearing tissues. It had founded that $96.6 \%$ of the denture stomatitis cases treated by tissue conditioners had cured and the highest curative result noted after a fifteen days period $^{[4,5]}$.

Generally, the tissue conditioners provided as a separate powder and liquid whose mixed and applied to the internal surface of the denture. The powder usually consists of poly (ethyl methacrylate) or a related copolymer, while the liquid is an ester plasticizer mixture and 4-50 wt percentage of ethyl alcohol. The powder component has no initiator and the liquid has no monomer; thus, mixing results in the dissolution of polymers into a solvent, followed by polymer chain entanglement and formation of a gel ${ }^{[6,7]}$.

Clinically, acrylic dentures formed from polymethyl-methacrylate(PMMA) present excellent resistance to the oral environment solvents and UV radiation. However, there is a risk of toxicity and hypersensitivity to the material due to products of oxidation and other components. Mucosal irritation caused by released methyl methacrylate has been reported ${ }^{[8,9]}$.

The visible light cure resin (VLCR) had introduced in 1983; this system consists of special resin and curing unit that emits high intensity light in the shorter blue wavelength. This light-activated urethane dimethacrylate (UDMA) resins had developed to eliminate contact allergies, laboratory vapors, and traditional, lengthy flasking and divesting processes used with the PMMA materials ${ }^{[10,11]}$.

From the clinical point of view, the removable denture often requires relines to improve their fitness to the supporting tissue because of gradual changes in edentulous ridges but the surface texture of the denture base resin is affected by the chemical composition of the reline resins. Consequentially, the surface irregularities of the denture base material increase the probability of plaque deposition, bacterial accumulation, and Candida adhesion than smooth surface, as the surface roughness providing niches in which the microorganisms have protected from sheer forces and oral hygiene measures ${ }^{[12-14]}$.

It has reported that, the plasticizer of tissue conditioner can reduces the glass transition temperature of acrylic resin, thereby increases the mobility of the polymer molecules and increases the solubility of the polymer in solvents in addition; the monomers of liners are usually solvents for the denture base resins. Therefore, it is possible that the plasticizer in the set conditioner gels could degrade the physical and mechanical properties of denture base resin because the resin surface has always exposed to conditioner component during use ${ }^{[15]}$.

Many studies have been conducted to test the physical and mechanical properties of tissue conditioner, such as compatibility with oral tissue, dimensional stability, bonding to denture bases, adhesion, water sorption, the viscoelastic properties, gelation characteristic, functional impression material and growth of Candida albicans on conditioner surfaces all are examined ${ }^{[16-18]}$.

Although, the effect of tissue conditioner on surface roughness of denture base material has not recorded. Therefore, the purpose of this study conducted to evaluate the effect of tissue conditioners on surface roughness of two chemically different and commercially available non-metallic denture base materials. The hypothesis tested was that the tissue conditioner would result in indifferent surface change of chemically different non-metallic denture base material. The surface roughness measurements were emphasis the resulting surface quality of 
non-metallic dentures would be influence by the tissue conditioner used and degrade their physical properties.

\section{MATERIALS AND METHODS}

A total numbers of 40 square-shaped specimens were constructed from two chemically different resins types with a minimum thickness of $2 \mathrm{~mm}$ to resemble the thickness of the denture base and divided into main two groups. Group A: 20 specimens of heat cured PMMA resin (Ecocryl - Hot protechno, Girona, Spain) were prepared $(10 \times 10 \times 2 \mathrm{~mm})$ by investing the wax pattern (Cavex-Holand BV) of the same dimensions in gypsum stone (LabStone- Dentsply, USA) by a conventional flasking procedure in dental flasks. After dewaxing, the acrylic PMMA powder mixed with its liquid, packed and processed in accordance with manufacturer's instructions.

Group B: 20 specimens of visible light cured UDMA resin (Eclipse, Dentsply, New York, USA) were prepared $(10 \times 10 \times 2 \mathrm{~mm})$ in well-designed glass Perspex mold with lid. The mold was preheated at $55^{\circ} \mathrm{c}$ for $2 \mathrm{~min}$ in a special oven (Conditioning Oven, DENTSPLY Trubyte, USA) after applying petroleum jelly. By finger pressure the light cured acrylic resin was compacted into the mold cavity. Polymerization was performed in light cured unit (Eclipse Processing Unit, Dentsply Trubyte, USA) containing six Eclipse halogen lamps (41V each; Dentsply Trubyte, USA) by exposing the sample to visible light at 400 to $500 \mathrm{~nm}$ for $10 \mathrm{~min}$.

After polymerization of both resin types, the specimens retrieved from the flask and mold then finished using a small acrylic-trimming bur to remove nodules and gross irregularities but not polished in an attempt to make the specimens with a side surface resembling the fitting denture surface for tissue conditioner application. For one side specimen's surface, finishing was performed by using 280,360 and 400 grit abrasive papers (Middle
East Factory- KSA), then was polished on a wet rag wheel with slurry pumice in an attempt to make the specimens with one side surface resembling the polished denture surface.

All the test specimens were stored in distilled water at $37^{\circ} \mathrm{C}$ for 48 hours for residual monomer release and as a conditioning environment resembling the oral cavity. After incubation period, the specimens were dried with air and the initial surface roughness (IRa) was measured for all polished specimens surfaces. The initial surface roughness (IRa) measurements performed by using a commercially available Pocket profilometer (MarSurf PS1, Mahr, Germaine, version prog v 1.01-08), three reading at different location on each specimens were measured by Stylus pick-up $2 \mu \mathrm{m}$ ( $80 \mu \mathrm{in})$ diamond stylus tip with a measuring force of $0.7 \mathrm{mN}$. Under constant pressure, the instrument's diamond stylus has moved across the polished specimen surface for recording three measurements for each specimen with a cutoff value of $5 \mathrm{~mm}$. The initial surface roughness (IRa) value of the particular specimen has considered as the average of three readings for each specimen Fig. 1.

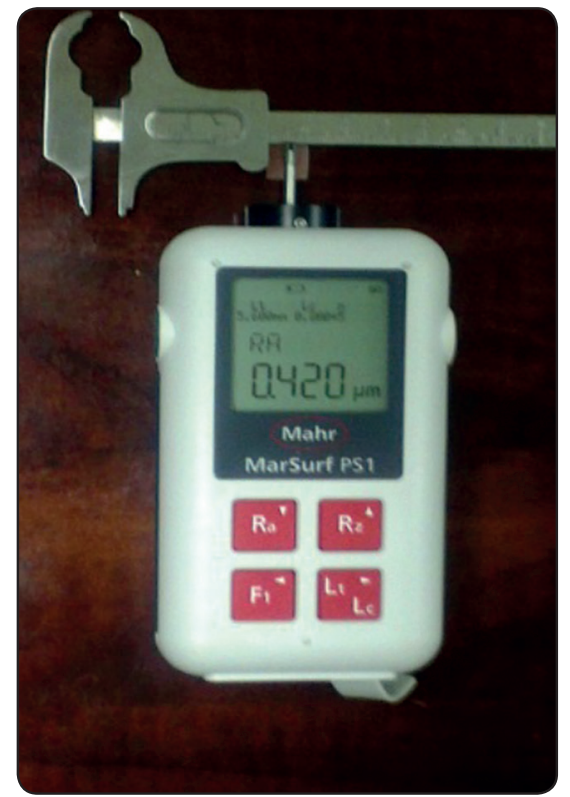

Fig. (1) The pocket profilometer with Stylus pick-up scanning the specimen surface. 
After the initial surface roughness values measured, the specimens of both resins were divided into two main groups: Group A represents the heat cured resin specimens and Group B represents the light cured resin. Randomly, the specimens were further divided into four subgroups $(n=10)$ according to the treatment option: Group AI: Heat cured resin control group. In this group the heat cured acrylic resin specimens were immersed in distilled water and didn't exposed to any treatment by tissue conditioner. Group AII: Heat cured acrylic resin specimens lined with tissue conditioner material. Group BI: Light cured resin control group. In this group the light cured acrylic resin specimens were immersed in distilled water and didn't exposed to any treatment by tissue conditioner. Group BII: Light cured acrylic resin specimens lined with tissue conditioner material.

From both resins type, the control groups (groups $\mathrm{AI}$ and $\mathrm{BI}$ ) were randomly selected and used for immersion in distilled water at $37^{\circ} \mathrm{C}$ for another 48 hours to simulate the clinical conditions, following the guidelines of the American Dental Association [ISO 20795-1: 2013] and the tissue conditioner test groups (group AII and BII) specimens were used for lining with tissue conditioner.

The test groups AII and BII specimens were subjected to surface treatment with chemically activated tissue conditioner lining (Alpha-dent product Co., clybourn AVE., Chicago, USA, Lot. L246XN). The tissue conditioner powder and liquid were proportioned and mixed according to the manufacturer's instructions and applied the gel mixture to the finished specimens surfaces in a layer of $2 \mathrm{~mm}$ thickness. After setting of conditioner gel, the lined specimens were immersed in distilled water and stored at $37 \mathrm{C}^{\circ}$ for one week.

After the immersion period, the specimens were removed, washed with distilled water and dried with air then the final surface roughness (FRa) has measured as before tissue conditioner relining as well as for the control group's specimens that incubated in distilled water. Changes in the surface roughness were calculated by the difference between the initial (IRa) and final (FRa) measurements found before and after relining for groups AII and BII as well as for group AI and BI after immersion. The data was collected and statistically analyzed using paired sample $t$-test and independent t-test at the significance level of $(\alpha=0.05)$. All statistical comparisons were made with the reference to the control groups.

\section{RESULTS}

The mean values and standard deviations of the initial and final surface roughness measurements of the tested groups AI, AII, BI and BII were shown in Table 1.

TABLE (1) The mean value, standard deviation of the initial (IRa) and final (FRa) surface roughness and $\mathrm{P}$ value records of the different test groups:

\begin{tabular}{c|c|c|c}
\hline Groups & IRa $\mu \mathrm{m}$ & FRa $\mu \mathrm{m}$ & P value \\
\hline Group AI & $0.115 \pm 0.347$ & $0.138 \pm 0.030$ & $0.036^{*}$ \\
\hline Group AII & $0.137 \pm 0.008$ & $0.146 \pm 0.017$ & 0.361 \\
\hline Group BI & $0.135 \pm 0.026$ & $0.167 \pm 0.020$ & $0.032^{*}$ \\
\hline Group BII & $0.133 \pm 0.025$ & $0.147 \pm 0.031$ & 0.318 \\
\hline
\end{tabular}

*: Significant difference $(p<0.05)$.

The results of paired sample $t$-test were showed that, there were a significant differences in surface roughness between group AI and AII, (0.036 and 0.361 ) respectively and between group BI and BII (0.032 and 0.318) respectively, $(\mathrm{p}<0.05)$. However, there were no significant differences in surface roughness between group AII and BII, (0.361 and0.318) respectively, $(\mathrm{p}>0.05)$.

According to the statistical analysis, there were a significant change in surface roughness of the heat 
and light cured specimens that were lined with tissue conditioner. However, there were no significant changes in surface roughness were noted with groups $\mathrm{AI}$ and $\mathrm{BI}$ specimens that were inserted in distilled water (control groups). The same statistical test for groups AII and BII comparison was revealed that, the tissue conditioner increase the surface roughness of light cured type resin more than heat cured type resin but had no impact statistically significance for them Fig 2.

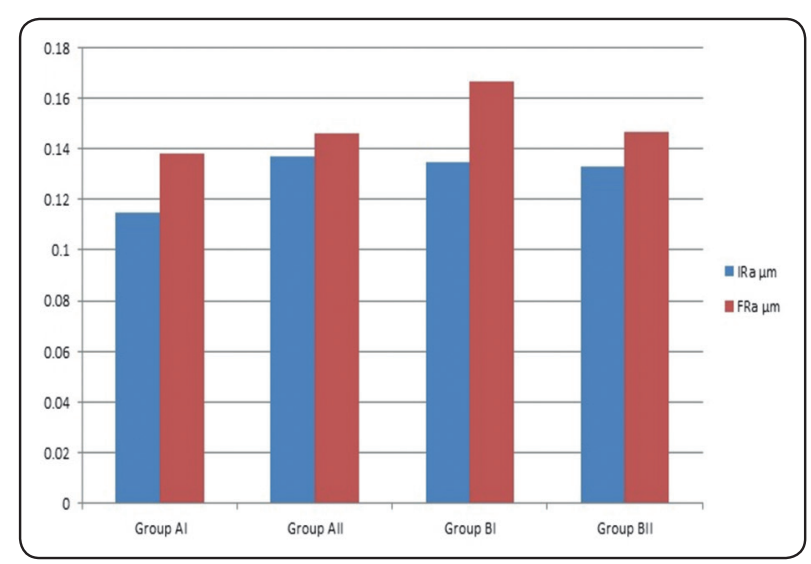

Fig. (2) Bar chart illustrating the mean value of initial (IRa) and final (FRa) surface roughness measurements of the different groups.

\section{DISCUSSION}

The most clinical requirements of currently available tissue conditioners were satisfied, but their properties are still less than ideal. The commonly used tissue conditioners are plasticized acrylic resins, these resins may be heat or chemically activated. Chemically activated tissue conditioners generally employ polymethyl-methacrylate as their principal structural components. These polymers supplied in powder form and mixed with liquids containing ethanol and plasticizer. Several investigators have suggested $2 \mathrm{~mm}$ is an appropriate thickness for a tissue conditioner ${ }^{[15,19]}$. This study has been supplied the requirements of these principles

The surface roughness of different denture base resins used in the study was initially tested as advocated by Barbeau et al. (2003) ${ }^{[20]}$ it is important that the surface roughness of materials used for dental prostheses are determined before their use in the mouth. As the rougher surfaces, can cause discomfort to the patients and contribute to microbial colonization and biofilm formation because the bacterial and fungal species have more of a propensity to adhere to rough denture base materials.

The method used in the study for surface roughness measurements was done by using pocket profilometer MarSurf PS1, it is small device with portable tools provide quick, accurate and easy method for storing and transferring data by USB connection, as recommended by the manufacture advice.

In order to explain the results of this study, previous studies had been suggested a threshold level of surface roughness of dental materials used in the oral cavity of $\mathrm{Ra}=0.2 \mu \mathrm{m}$ where no further reduction in plaque accumulation is expected under that level ${ }^{[21,22]}$. The limitation of the present study is the absence of controlled clinical studies on the surface roughness threshold for PMMA and VLCR therefore, it was considered appropriate to accept the threshold $\mathrm{Ra}=0.2 \mu \mathrm{m}$.

The results of the present study revealed that, there were a significant differences in surface roughness $(p<0.05)$ between the heat cured acrylic resins control (0.036) and tissue conditioner relined (0.361) tested groups. As well as, there were a significant differences in surface roughness between the light cured resins control (0.032) and tissue conditioner relined (0.318) tested groups. However, there were no statistical significant differences in surface roughness found between heat cured and light cured resin (0.361 and 0.318 ) respectively after tissue conditioner application. Consequently, in comparison to the accepted $\mathrm{Ra}$ values measured ( $\mathrm{Ra}$ $=0.2 \mu \mathrm{m})$, the Ra values of the tissue conditioner tested specimens in this study were considerably higher. This may be interpreting the effect of tissue 
conditioner on surface roughness of the different used denture base resins. These results coincidence with the corresponding foundations of Wieckiewicz et al. (2014) ${ }^{[23]}$.

Moreover, the light cured resin specimens were exhibiting rougher surface than heat cured after relined with tissue conditioner as considering the mean value, this may be due to the differences in the chemical and physical properties of the different materials ${ }^{[24,25]}$.

The results of the present study also confirmed that, the increased surface roughness of denture base resins lined with tissue conditioner and incubated in water might be due to loss of its soluble materials as plasticizer and ethyl alcohol and water absorption. The loss of these soluble materials increases the number of tiny bubbles, which reflected as surface roughness ${ }^{[26,27]}$.

In the study of Wilson and Tomlin (1969) ${ }^{[28]}$, and updated by Hong et al. (2004) ${ }^{[18]}$ the rate of alcohol loss from tissue conditioners had been recorded after applying them to complete denture record bases and immersed them in water in sealed container. The authors found that, the alcohol was leach out much more quickly than expected with the greatest loss occurring in the first 12 hours and peaking at approximately 60 hours. Furthermore, if the gel was weak and not strongly held together by entanglements, both alcohol and esters could be leached out quickly and it's solvent action could effect on denture base material. This concept comes with the agreement with this study.

This in vitro study has a limitation of its clinical regimens as the presence of saliva with its buffering action and other oral cleansing factor of mastication may alter the results. Another limitation was that only one commercially brand of tissue conditioner had used with one time application, as the results may not be applicable to other tissue conditioners types or with recurrent application. Therefore, future clinical studies required to evaluate the effect of tissue conditioners on surface integrity of the used denture base material. In addition, these studies should be implicated with more than one commercial tissue conditioner require testing as the prevalence need for conditioning the denture bearing tissue that need a variable and multiple application of tissue conditioner.

In accordance to the introduced objectives of the study, the surface roughness measurements have emphasized that, the leached out solvents contents of the tissue conditioner used can influence on the polished surface quality of non-metallic denture bases and degrade their physical properties.

\section{CONCLUSIONS}

The polished surface of the denture base material has changed with the using of tissue conditioner. The heat cured acrylic resin which used as denture base material was more resistant to solvent contents of tissue conditioner than visible light cured resin. It has recommended to repolishing the polished denture surface after each application of tissue conditioner material particularly with the long and repeated time of uses.

\section{REFERENCES}

1. Malmstrom H, Mehta N, Sanchez R, Moss M. The effect of two different coatings on the surface integrity and softness of a tissue conditioner. J Prosthet Dent 2002; 87: 153-7.

2. Murata H, Hong G, Li YA, Hamada T. Compatibility of tissue conditioners and dental stones: effect on surface roughness. J Prosthet Dent 2005; 93: 274-81.

3. Hatamleh MM, Maryan CJ, Silikas N, Watts DC. Effect of net fiber reinforcement surface treatment on soft denture liner retention and longevity. J Prosthodont 2010; 19: 258-62.

4. Noort RV. Introduction to dental materials. 2nd ed., Edinburgh, London, New York, Philadelphia, St Louis, Sydney and Toronto: Mosby; 2002, P. 212-213.

5. Tsovili-Raselou KT, Dimitriou P. Treatment of denture stomatitis by the use of tissue conditioning. Hell Stomatol Chron 1990; 43: 103-7. 
6. Rodrigues S, Shenoy V, Shetty T. Resilient liners: a review. J Indian Prosthodont Soc 2013; 13: 155-64.

7. Murata H, Taguchi N, Hamada T, Kawamura M, McCabe JF. Dynamic viscoelasticity of soft liners and masticatory function. J Dent Res 2002; 81: 123-28.

8. Yunus N, Rashid AA, Azmi LL, Abu-Hassan MI. Some flexural properties of a nylon denture base polymer. J Oral Rehabil 2005; 32: 65-71.

9. Goiato MC, Santos DM, Haddad MF, Pesqueira AA. Effect of accelerated aging on the microhardness and color stability of flexible resins for dentures. Braz Oral Res 2010; 24: 114-9.

10. Diaz-Arnold AM, Vargas MA, Shaull KL, Laffoon JE, Qian F. Flexural and fatigue strengths of denture base resin. J Prosthet Dent 2008; 100: 47-51.

11. Uzun G, Hersek N. Comparison of the fracture resistance of six denture base acrylic resins. J Biomater Appl 2002; 17: 19-29.

12. Leles CR, Machado AL, Vergani CE, Giampaolo ET, Pavarina AC. Bonding strength between a hard chairside reline resin and a denture base material as influenced by surface treatment. J Oral Rehabil 2001; 28: 1153-7.

13. Kim JH, Choe HC, Son MK. Evaluation of adhesion of reline resins to the thermoplastic denture base resin for non-metal clasp denture. Dent Mater J 2014; 33: 32-8.

14. Nikawa H, Mikhira S, Egusalt, Fukushima H, Kawabata R, Hamada T, et al. Candida adherence and biofilm formation on oral surfaces. Nippon Ishinkin Gakkai Zasshi 2005; 46: 233-42.

15. Anusavice KJ. Phillips' science of dental materials. 11th ed., Philadelphia: Elsevier (USA); 2003, P. 269-271,722.

16. Jepson NJ, McGill JT, McCabe JF. Influence of dietary simulating solvents on the viscoelasticity of a temporary soft lining materials. J Prosthet Dent 2000; 83: 25-31.

17. Hiromoi K, Fujii K, Inoue K. Viscoelastic properties of denture base resins obtained by underwater test. J Oral Rehabil 2000; 27: 522-31.
18. Hong G, Murata H, Hamada T. Relationship between plasticizer content and tensile bond strength of soft denture liners to a denture base resin. Dent Mater J 2004; 23: 93-9.

19. Singh K, Chand P, Singh BP, Patel CB. Study of the effect of surface treatment on the long term effectiveness of tissue conditioner. J Oral Sci 2010; 52: 261-5.

20. Barbeau J, Séguin J, Goulet JP, de Koninck L, Avon SL, Lalonde B, et al. Reassessing the presence of Candida albicans in denture-related stomatitis. Oral Surg Oral Med Oral Pathol Oral Radiol Endod 2003; 95: 51-59.

21. Bollen CM, Lambrechts P, Quirynen M. Comparison of surface roughness of oral hard materials to the threshold surface roughness for bacterial plaque retention: a review of the literature. Dent Mater 1997; 13: 258-269.

22. Jefferies SR. Abrasive finishing and polishing in restorative dentistry: a state-of the art review. Dent Clin North Am 2007; 51: 379-97.

23. Wieckiewicz M, Opitz V, Richter G, Klaus W. Physical Properties of Polyamide-12 versus PMMA Denture Base Material. Biomed Res Int 2014;9:150298.

24- Cilingir A, Bilhan H, Geckili O, Sulun T, Bozdag E, Sunbuloglu E. In vitro comparison of two different materials for the repair of urethane dimethacrylate denture bases. J Adv Prosthodont 2013; 5: 396-401.

25- Peracini A, Davi LR, de Queiroz Ribeiro N, de Souza RF, Lovato da Silva CH, de Freitas Oliveira Paranhos H. Effect of denture cleansers on physical properties of heatpolymerized acrylic resin. J Prosthodont Res. 2010; 54: 78-83.

26. Wilson J. In vitro loss of alcohol from tissue conditioners. Int J Prosthodont 1992; 5: 17-21.

27. Khaledi A, Borhanihaghighi Z, Vojdani M. The effect of disinfectant agents on dimensional stability and surface roughness of a tissue conditioner material. Indian J Dent Res 2011; 22: 499-504.

28. Wilson HJ, Tomlin HR. Soft lining materials; some relevant properties and their determination. J Prosthet Dent 1969; 21: $244-50$. 